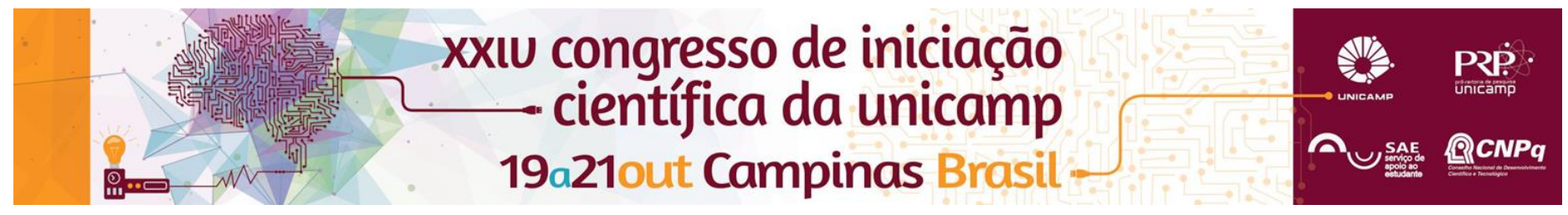

\title{
Perfil Socioeconômico das mulheres vítimas de violência doméstica atendidas em Centro de Referência em Campinas
}

\author{
Silvia M.F. dos Santos, Daniella Y. Baragatti, Danielle F. Farias, Antonieta K. K. Shimo, Eliete M. Silva.
}

\section{Resumo}

Trabalho realizado em Centro de Referência e Apoio à Mulher (CEAMO), na cidade de Campinas, estado de São Paulo. Com objetivo de conhecer o perfil socioeconômico das vitimas atendidas no CEAMO nos anos de 2013 a 2015.

\section{Palavras-chave:}

Violência doméstica, violência contra a mulher, atenção primária à saúde.

\section{Introdução}

A definição de violência segundo a Organização Mundial de Saúde (OMS) é o uso de força física ou de poder, sendo ameaça ou colocado em prática, contra si próprio ou contra outra pessoa, grupo ou comunidade, que resulte ou possa resultar em sofrimento, morte, dano psicológico, desempenho prejudicado ou privação (OMS, 2002).

Violência contra a mulher é um problema social e, portanto, um problema de saúde pública que pode se apresentar de várias formas. Uma delas é a violência doméstica praticada por parceiros íntimos, por inúmeros motivos. É considerada violência doméstica qualquer tipo de comportamento que cause dano físico, moral ou sexual ao parceiro (Dutra e cols, 2013).

Este estudo tem como objetivo conhecer o Perfil Socioeconômico das mulheres vítimas de violência atendidas em Centro de Referência em Campinas- SP.

\section{Resultados e Discussão}

A coleta de dados foi realizada no Centro de Referência e Apoio à Mulher (CEAMO), na cidade de Campinas, estado de São Paulo.

Encontrou-se muitos dados sem preenchimento. Sendo estes em sua maioria relacionados com renda da vitima, tipo de agressão sofrida e quem é o agressor. A análise refere-se aos dados preenchidos.

O perfil encontrado foi: idade média de 40,10 anos, escolaridade predominante Ensino Médio Completo, estado civil casada ou convivente/companheiro, casa própria, desempregada e mora com em média 1,98 moradores. Segundo estudo realizado em Teresina (PI), $89 \%$ das mulheres analisadas neste estudo não fez referência ao agressor. Acredita-se que seja por dependência econômica, medo de vingança do companheiro, que por inúmeras vezes faz ameaças a vida da vítima. (Monteiro e Cols, 2006).

A análise por perfil socioeconômico revela que são as mulheres com menor nível de instrução as mais atingidas: $27 \%$ das respondentes com ensino fundamental informaram que já foram vítimas, percentual que cai para $18 \%$ e $12 \%$ quando consideradas as mulheres com ensino médio e ensino superior, respectivamente. (Mapa da Violência, 2015). Já os dados encontrados no CEAMO as vítimas possuem nível de escolaridade alto, o que demonstra que as mulheres que buscam atendimento possuem nível de conhecimento maior em relação as que não chegam a fazer denúncia.

Figura 1. Ciclo da Violência

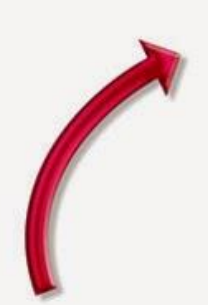

EXPLOSÃO

ÉAFASE

VIOLENTA, COM XINGAMENTOSE

SURRAS

LUA DE MEL TUDO FICA PERFEITO ATÉA NOVAAGRESSĀO

$$
\text { SURRAS }
$$
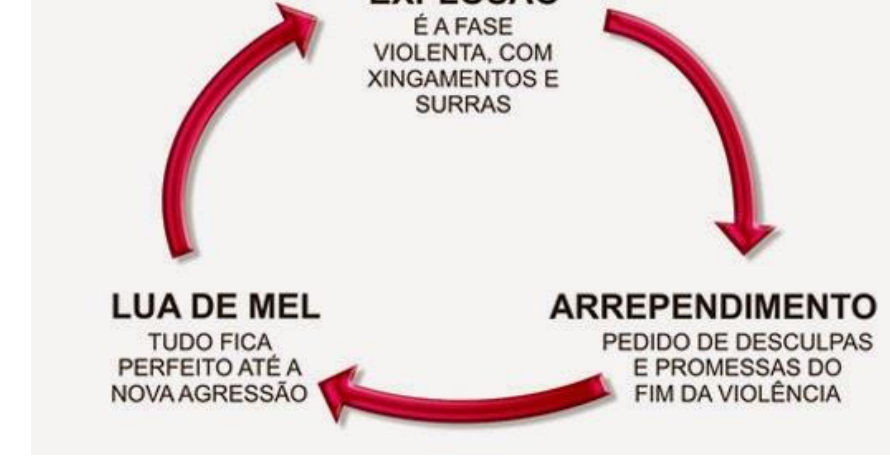

\section{Conclusão}

Para o profissional que lida diretamente com a vítima de violência doméstica é de grande importância conhecer seu ciclo, para impedir que este continue se repetindo. O combate à violência contra a mulher também se dá pelo fato de compreender a situação em que essa mulher se encontra, se possui dependência econômica do parceiro entre outros fatores que tornam essa mulher mais vulnerável a violência.

Com este estudo percebeu-se a importância da qualidade do preenchimento dos dados em prontuário. Conhecer os motivos que levam ao não preenchimento, é de grande importância. Demanda-se mais estudos sobre o assunto, uma vez que em poucos estudos é tratado o fato de que pode ser que os profissionais não saibam abordar determinados assuntos que possam considerar difíceis ou de pouca importância.

J.J. Waiselfisz. Mapa da violência 2015: homicídios de mulheres no Brasil. Brasília - DF. 2015.

Monteiro CFS, Araújo TME, Nunes BMVT, Lustosa AR, Bezerra CMJ. A violência contra a mulher atendida em unidade de urgência: uma contribuição da enfermagem. Esc. Anna Nery v.10 n.2 Rio de Janeiro. Agosto 2006.

Organização Mundial de Saúde - OMS. Relatório mundial sobre violência e saúde. Genebra, 2002.

Dutra, M. L.; Prates, P. L.; Nakamura, E. ; Villela W. V.. A configuração da rede social de mulheres em situação de violência doméstica. Ciênc. saúde coletiva vol.18 n.5 Rio de Janeiro. Maio, 2013. 